\title{
Factors influencing malnutrition in Filipino elderly
}

\author{
Nancy A. Tandang ${ }^{1 *}$, Reanne Len C. $\operatorname{Arlan}^{1} \&$ Gerard C. Navarro ${ }^{2}$ \\ ${ }^{1}$ Institute of Statistics, College of Arts and Sciences, University of the Philippines Los \\ Banos; ${ }^{2}$ Institutional Shareholder Services, Philippines
}

\begin{abstract}
Introduction: The elderly population is susceptible to malnutrition due to the physiological and functional changes caused by ageing. Hence, to prevent the degenerative nutritional conditions of the elderly and improve their quality of life, this study aimed to determine the influencing factors of malnutrition among Filipino elderly. Methods: Anthropometric component data from the 8th National Nutrition Survey (NNS) were utilised along with the nutritional status of Filipino elderly, based on body mass index as the dependent variable and variables from the clinical and health, dietary, and socioeconomic components of NNS as explanatory factors. Multinomial logistic regression analysis was then performed in fitting models. Results: High magnitude and severity of malnutrition were observed among Filipino elderly $-20.2 \%$ were underweight and $24.8 \%$ were overweight. Significant influencing factors in estimating an elderly's odds of being underweight were the elderly's age group, presence of hypertension, presence of anaemia, and adequacy of vitamin A intake. Whereas, significant influencing factors in estimating an elderly's odds of being overweight/obese included highest educational attainment, presence of anaemia, hypertension, diabetes, and dyslipidaemia. Conclusion: Knowing the influencing factors may help the elderly become more aware and conscious of their health, as well as to promote nutrient intakes to prevent malnutrition that can worsen their health conditions. Additionally, concerned institutions in the country could use the findings of this study as one of the bases in strengthening their approach and implementation or even provide relevant and timely policies and programmes that address malnutrition in the elderly of this country.
\end{abstract}

Keywords: Multinomial logistic regression, nutritional status, elderly

\section{INTRODUCTION}

The ageing population is increasing worldwide. According to the World Health Organization (WHO), the total number of people $\geq 60$ years is estimated to increase from 900 million in 2015 to 1.4 billion by 2030 , to 2.1 billion by 2050 , and to 3.2 billion in 2100 . This information shows how the number of elderly is expected to grow rapidly worldwide. It is also claimed that people aged $\geq 60$ years are expected to outnumber children aged $\leq 5$ years by 2020. Furthermore, it is projected that by 2050, a great portion of this increase will be shared by developing countries (WHO, 2018). In the Philippines, the percentage of older people is likewise increasing, even faster than the total population growth of the country. In 2000, about 4.6 million Filipino belonged to the age group of $\geq 60$ years, which constituted around $6.0 \%$ of the total population. This number has increased to 9.4 million after two decades, constituting about $8.6 \%$ of the

\footnotetext{
*Corresponding author: Nancy A. Tandang, Ph.D Institute of Statistics, College of Arts and Sciences, University of the Philippines Los Banos Tel: (+63)0922-829-3160; Fax: (+63)(049)536-2381; E-mail: natandang@up.edu.ph doi: https://doi.org/10.31246/mjn-2020-0051
} 
total population. By 2050, it is projected that about $16.5 \%$ of the total population in the country will be composed of the elderly. The increasing trend in the elderly population worldwide could be attributed to decreasing fertility and an increased life expectancy (HelpAge International, 2012).

Having a longer life gives the elderly more chances to contribute to their families and society. However, it is important as well to realise that a fast increase in the older population raises several concerns and creates challenges that affect their families and policy makers. There will be challenges in earning enough income to support elderly needs, especially in developing countries. Loss of social status and acknowledgement could also be some of those disheartening challenges that could be experienced by the elderly people. Along with these concerns, health services of a country will have higher demands. These are just some of the concerns and challenges that need to be considered by the economic and social institutions of a country. Plans and programmes that would address income security, health care and other needs of the elderly population must be developed (Panigrahi, 2009; Agarwalla, Saikia \& Baruah, 2015).

Health, independency and quality of life of older people are contingent with their nutritional condition. Elderly people are susceptible to malnutrition due to the physiological and functional changes caused by ageing. This is in addition to the other concerns regarding insufficient financial support and inadequate access to nutritious foods (Agarwalla et al., 2015). The risk of malnutrition among the ageing population increases even further in the case of multi-morbidity, which is mutual among the elderly (Marengoni et al., 2008). Hence, to prevent the degenerative nutritional conditions of the elderly and to improve their quality of life, it is vital for health and nutrition institutions to form timely interventions that would lessen the age group's risk of being malnourished.

To contribute towards the timely intervention of concerned institutions in the country, this study aimed to determine the nutritional conditions of Filipinos and identify factors that may influence malnutrition in the elderly. In doing so, policy makers would be made aware of the characteristics of the elderly people who are prone to undernutrition or overnutrition. Malnutrition is a state in which a deficiency (undernutrition), excess (overnutrition), or imbalance of energy, protein, and other nutrients affect the human body in a negative manner. Both undernutrition and overnutrition are related to the increased risk of excess mortality, poor cognition, chronic diseases, and poor health-related quality of life (Selvamani $\&$ Singh, 2018). This study also sought to identify factors that lead to malnutrition in the elderly. Knowing suggestive determinants of malnutrition among the elderly would be significant to policy makers as these would allow them to develop relevant and timely interventions for the nutritional well-being of the elderly.

Several studies have been conducted to identify factors associated with the nutritional status among elderly people. Some of the factors identified include biochemical, clinical, dietary intake, food security, and socioeconomic factors. Social and economic conditions greatly affect an older person's choices of diet and even eating patterns, which can lead to poor nutrition. The process of ageing also affects other nutrient needs. As an example, the required intake for some nutrients should be reduced. However, according to some data, requirements for other essential nutrients may, in fact, increase as age increases. Thus, there is a serious need to review current recommended daily nutrient allowances for the elderly group. Lifestyle and daily 
activities of elderly people also affect their nutritional status (Boscatto et al., 2013). Additionally, systolic hypertension was found to be associated with underweight (Ly et al., 2013). Shibata et al. (2018) stated that underweight was inversely and significantly associated with high cholesterol, which is also a risk factor of obesity.

Indeed, various studies have provided meaningful information on the factors that affect the nutritional status of an individual. However, influencing factors of the elderly's nutritional status may vary according to the location of the study conducted due to several reasons, such as culture, lifestyle, and economic status of a country. The results of this study may provide additional information on the subject and will be very helpful in identifying the causes of poor nutrition.

\section{MATERIALS AND METHODS}

\section{Data source}

Data from the $8^{\text {th }}$ National Nutrition Survey (NNS) conducted by the Food and Nutrition Research Institute (FNRI) in 2013 were utilised in this study. The NNS is the key source of information that serves as the government's basis for the formulation of health and nutrition plans and programmes for Filipinos. This survey has ten components: anthropometry, biochemical, clinical and health, dietary, socioeconomic, food security, government programme participation, infant and young child feeding (IYCF), maternal health and nutrition, and household awareness and usage of iodised salt, nutrition label, and nutrition facts.

The anthropometry component deals with data that reflect the nutritional status of Filipinos across all ages. This study considered elderly Filipinos aged $\geq$ 60 years old as the age group of interest, and their nutritional status was assessed based on their body mass index (BMI). Moreover, to explain the variation in the nutritional status of elderly and what causes them to become malnourished, some explanatory variables were generated from the clinical and health, dietary, and socioeconomic components of the NNS. The clinical and health component was used to determine the clinical signs of nutritional deficiencies such as vitamin A deficiency, iron deficiency, and iodine deficiency, along with some other lifestyle-related diseases, including hypertension, diabetes, and dyslipidaemia among others. Alternatively, the dietary data were used to measure food and nutrient intakes at the household and individual levels. Lastly, the socioeconomic component was considered for the living conditions of the household (FNRI-DOST, 2013).

The survey used a stratified threestage sampling design. For the first stage, primary sampling units (PSUs), consisting of one barangay or a combination of contiguous barangays with at least 500 households, were selected. Within the selected PSUs, enumeration areas with 150 to 200 households were determined, and the housing units were randomly selected. Afterwards, households were randomly selected in the last stage (Barcenas, 2004). The NNS's design complexity was considered in the percentage distribution and fitting of model in this study. With merging done to all NNS components considered, data collected from 1,807 Filipino elderly samples were subjected to analysis.

\section{Data collection}

Standard techniques in measuring the elderly individual's height and weight were followed in data collection. Detecto $^{\mathrm{TM}}$ platform beam balance scale was used in measuring weight. At most, three measurements were obtained in which a third measurement was only taken if the difference between the first two measurements was greater than $0.3 \mathrm{~kg}$. The final measurement was the average recorded to the nearest 
$0.1 \mathrm{~kg}$. The weighing scale used for weight determination was calibrated using $5 \mathrm{~kg}$ standard weights. On the other hand, standing height was obtained using a Microtoise. Similar to weight measurements, at most, three measurements were also obtained in which a third measurement was only taken if the difference between the first two measurements was greater than $0.5 \mathrm{~cm}$. The final measurement was the average of the measurements and was recorded to the nearest $0.1 \mathrm{~cm}$. For height measurement, the instrument used was calibrated with a standard twometer steel ruler. However, the height of individuals with body defects, such as polio and hunchback, was not measured (FNRI-DOST, 2013).

Personal interviews were conducted to determine the socio-demographic characteristics of the elderly. Smoking and alcohol consumption behaviours of the elderly population were identified based on the WHO operational guidelines. Food consumption of the elderly was determined using a 24hour food recall through an interview. Moreover, the Food Composition Library, the Philippine Recommended Energy and Nutrient Intake (RENI) 2002 edition and the Philippine Dietary Reference Intake (PDRI) were employed in the dietary evaluation and assessment of the adequacy of nutrient intakes. The elderly's health conditions, which included diabetes, dyslipidaemia, fasting blood sugar (FBS), and blood lipid levels, were determined through blood samples extracted using venepuncture, following standard procedures. In addition, blood pressure level of the elderly was measured twice using a non-mercurial sphygmomanometer and stethoscope. Finally, haemoglobin level of the elderly was determined on-site using a spectrophotometer (FNRI-DOST, 2013).

\section{Ethics approval}

The FNRI has a review committee named the Institutional Ethics Review Committee (FNRI-IERC). However, because it was FNRI who has the official mandate to define the nutritional status of Filipinos in general, an ethics review was not required in conducting the NNS. Nonetheless, the FNRI ensured that the ethics and practices when conducting a survey were followed and implemented. These included informed consent forms that assured the confidentiality of the data collected and that the respondents may refuse to continue data collection at any time. Moreover, FNRI submitted the $8^{\text {th }}$ NNS questionnaires to the Philippine Statistics Authority (PSA) for their review and approval (FNRI-DOST, 2013).

\section{Data analyses}

The weighted percentage distribution of the Filipino elderly population, according to their nutritional status, was constructed. To know the characteristics of malnourished elderly, the nutritional status of the elderly was cross-tabulated with the explanatory variables considered in the study, incorporating the sampling weights to adjust for the complexity of the sampling method employed in the NNS. A multinomial logistic regression analysis was performed to identify significant determinants of malnutrition in the elderly. This study considered the nutritional status of Filipino elderly as the dependent variable, $Y$, with values 0,1 , and 2 to indicate an elderly with normal weight, underweight, and overweight/obesity, respectively. The elderly was classified as underweight if BMI was < $18.5 \mathrm{~kg} / \mathrm{m}^{2}$, normal if BMI was $18.5-24.99 \mathrm{~kg} / \mathrm{m}^{2}$, and overweight/ obese if BMI was $\geq 25 \mathrm{~kg} / \mathrm{m}^{2}$ (WHO/ NCHS, 1978).

Two logistic equations were considered in which the category normal or $(Y=0)$ served as the reference category. The equations are as follows: 


$$
\begin{aligned}
& \ln \frac{\pi(y=1)}{\pi(y=0)}=\alpha_{1+\beta_{11} X 1+\beta_{12} X 2+\cdots+\beta_{1 K} X_{k}} \\
& \ln \frac{\pi(y=2)}{\pi(y=0)}=\alpha_{2+\beta_{21} X 1+\beta_{22} X 2+\cdots+\beta_{2 K} X_{k}}
\end{aligned}
$$

From the logistic equations, the likelihood of each outcome was computed as:

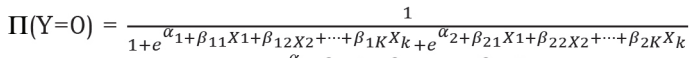

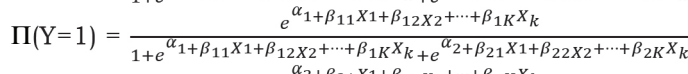

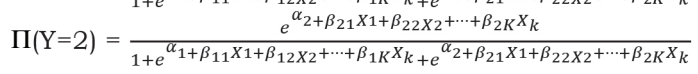

The significance of the overall model, as well as the predictors were assessed. The sign of the coefficient of a certain factor was also checked for consistency in the literature. STATA was used to facilitate all the analyses.

\section{RESULTS}

\section{Nutritional status across some factors}

A high magnitude and severity of malnutrition among the elderly Filipinos were observed wherein $20.19 \%$ of the elderly population were underweight, and approximately a quarter (24.83\%) were determined as overweight or obese (Figure 1). In particular, 10.96\% and $15.31 \%$ of the elderly population were females who were underweight and overweight/obese, respectively. Meanwhile, the proportions of underweight and overweight/obese male elderly were $9.24 \%$ and $9.52 \%$, respectively. About one in every ten individuals $(9.92 \%)$ aged $60-70$ years were underweight, while around one in every 25 individuals (4.36\%) were classified as overweight/obese. Also, there were more elderly above 70 years old who were underweight than overweight, comprising $14.42 \%$ and $3.89 \%$ of the elderly population, respectively. As for educational attainment, the largest portion of underweight individuals was observed among elderly with no grades completed $(9.21 \%)$, a little higher than those with elementary level as their highest educational attainment (7.99\%). Likewise, $10.60 \%$ of the elderly individuals who attained elementary education were overweight/obese. The largest portion $(23.57 \%)$ of elderly with normal nutritional status were still actively working. Among the underweight elderly, $6.30 \%$ had no occupation. In contrast, the highest proportion of overweight elderly had a job (Table 1).

This study also determined the nutritional status of elderly byconsidering

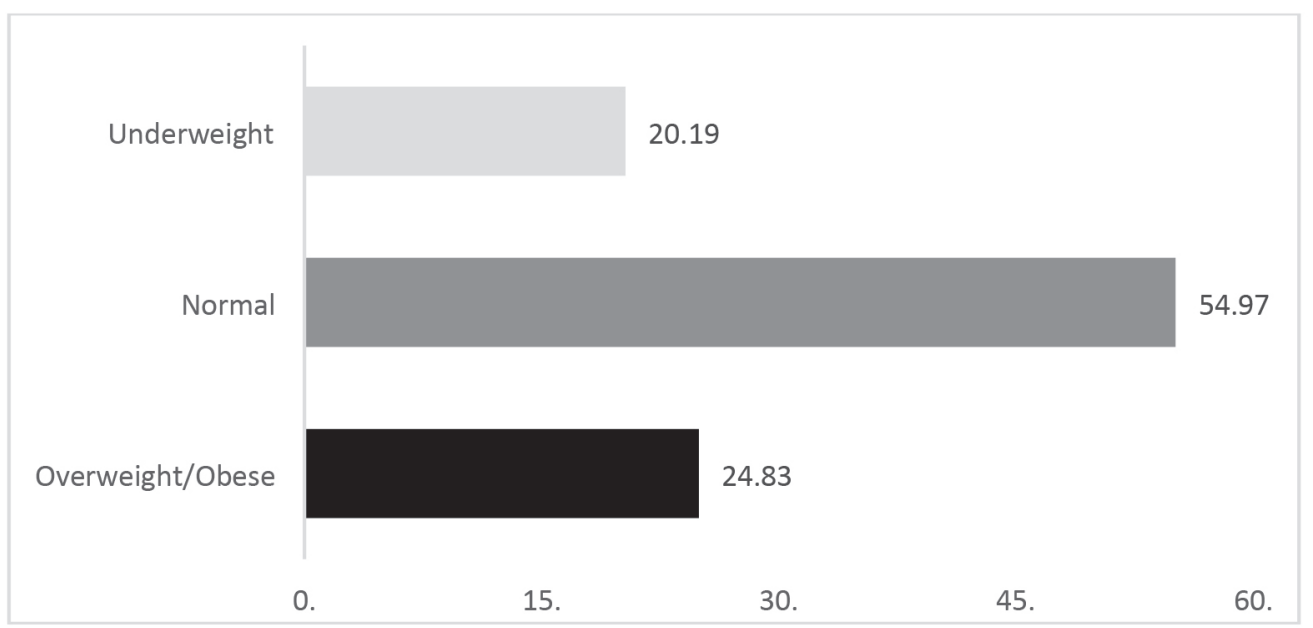

Figure 1. Weighted percentage distribution of Filipino elderly by nutritional status based on the 2013 NNS 
Table 1. Weighted percentage distribution of Filipino elderly by nutritional status and by certain factors based on the 2013 NNS

\begin{tabular}{|c|c|c|c|}
\hline \multirow{2}{*}{ Factor } & \multicolumn{3}{|c|}{ Nutritional status } \\
\hline & Normal & Underweight & Overweight/Obese \\
\hline \multicolumn{4}{|l|}{ Sex } \\
\hline Male & 26.41 & 9.24 & 9.52 \\
\hline Female & 28.57 & 10.96 & 15.31 \\
\hline \multicolumn{4}{|l|}{ Age group (years) } \\
\hline $60-70$ & 34.36 & 9.92 & 4.36 \\
\hline $71-80$ & 16.25 & 7.73 & 2.55 \\
\hline Above 80 & 4.36 & 6.69 & 1.34 \\
\hline \multicolumn{4}{|l|}{ Highest educational attainment } \\
\hline No grades completed & 19.18 & 9.21 & 4.91 \\
\hline Elementary & 22.44 & 7.99 & 10.60 \\
\hline High school & 8.54 & 2.24 & 4.56 \\
\hline College and post-graduate & 4.81 & 0.70 & 3.91 \\
\hline \multicolumn{4}{|l|}{ Occupation } \\
\hline Unemployed & 15.85 & 6.30 & 4.88 \\
\hline Housekeeper & 9.40 & 4.08 & 5.73 \\
\hline Pensioner & 6.16 & 1.69 & 4.85 \\
\hline Employed & 23.57 & 8.13 & 9.36 \\
\hline \multicolumn{4}{|l|}{ Alcohol status ${ }^{\dagger}$} \\
\hline Non-alcoholic & 24.56 & 9.01 & 12.18 \\
\hline Alcoholic & 18.38 & 6.02 & 6.96 \\
\hline Drinks alcohol occasionally & 9.10 & 4.25 & 4.84 \\
\hline \multicolumn{4}{|l|}{ Smoking status ${ }^{\dagger}$} \\
\hline Never smoked & 28.12 & 8.65 & 16.08 \\
\hline Former smoker & 11.99 & 6.09 & 2.71 \\
\hline Current smoker & 11.92 & 4.53 & 5.20 \\
\hline
\end{tabular}

${ }^{\dagger}$ percent total is not equal to $100 \%$ due to missing values

some factors related to their health conditions such as anaemia, diabetes, dyslipidaemia, and hypertension. Among the elderly, $6.14 \%$ were underweight and had anaemia, while $2.77 \%$ were overweight and had anaemia. As for diabetes, a higher proportion of the elderly population was overweight and diabetic (5.91\%) compared underweight and diabetic $(1.80 \%)$. Similarly, a higher proportion was classified as overweight with dyslipidaemia compared to the proportion who were underweight with dyslipidaemia, comprising $2.84 \%$ and $0.60 \%$ of the elderly, respectively. Moreover, $12.80 \%$ of the elderly had hypertension and were recorded to be overweight - twice higher than those who were underweight with hypertension at $6.26 \%$. Concerning dietary intake, a higher proportion with inadequate iron intake and malnutrition were overweight than underweight, constituting $4.22 \%$ as compared to $1.51 \%$ of the elderly. Among the elderly with inadequate niacin intake, a higher percentage was underweight $(13.38 \%)$ than overweight $(10.19 \%)$. On the other hand, among those with adequate or more intake of niacin, the number of those classified as overweight (14.64\%) was greater than those who were underweight $(6.82 \%)$. As for those with inadequate thiamine intake, the number of those classified as overweight was $1.55 \%$ greater than those classified as underweight. In 
addition, $1.14 \%$ of the elderly had inadequate intake of vitamin $\mathrm{A}$ and were underweight - a bit higher than the $0.20 \%$ who were overweight. On the contrary, a considerably higher proportion of those with more than adequate vitamin A intake were overweight $(12.15 \%)$ than underweight (6.15\%) (Table 2$)$.

\section{Influencing factors}

Among the independent factors considered in the study, age group, hypertension, anaemia, and adequacy of Vitamin A intake were found to be significant determinants in estimating the odds of an elderly becoming underweight. Table 3 gives the regression coefficients, standard error, odds ratio, a 95\% confidence interval for odds ratio, and the $p$-value of the predictors considered in the model. According to the fitted model, the likelihood of an elderly to become underweight was higher if he/ she was $\geq 70$ years old or diagnosed with anaemia or had inadequate vitamin A intake, holding other factors constant. Specifically, the odds of an elderly to be underweight was 1.52 times and 1.80 times more likely if he/she was $71-80$ years old and $>80$ years, respectively, as

Table 2. Percentage distribution of the nutritional status of elderly in the Philippines by health conditions and by dietary intake based on the 2013 NNS

\begin{tabular}{|c|c|c|c|}
\hline \multirow{2}{*}{ Factor } & \multicolumn{3}{|c|}{ Nutritional status } \\
\hline & Normal & Underweight & Overweight/Obese \\
\hline \multicolumn{4}{|l|}{ Health Condition } \\
\hline $\begin{array}{l}\text { Anaemia } \\
\text { Without anaemia } \\
\text { With anaemia }\end{array}$ & $\begin{array}{l}44.34 \\
10.64\end{array}$ & $\begin{array}{l}14.05 \\
6.14\end{array}$ & $\begin{array}{c}22.06 \\
2.77\end{array}$ \\
\hline $\begin{array}{l}\text { Diabetes } \\
\text { Without diabetes } \\
\text { With diabetes }\end{array}$ & $\begin{array}{l}47.78 \\
7.19\end{array}$ & $\begin{array}{c}18.40 \\
1.80\end{array}$ & $\begin{array}{c}18.92 \\
5.91\end{array}$ \\
\hline $\begin{array}{l}\text { Dyslipidaemia } \\
\text { Without dyslipidaemia } \\
\text { With dyslipidaemia }\end{array}$ & $\begin{array}{l}51.70 \\
3.28\end{array}$ & $\begin{array}{c}19.59 \\
0.60\end{array}$ & $\begin{array}{l}21.99 \\
2.84\end{array}$ \\
\hline $\begin{array}{l}\text { Hypertension } \\
\text { Without hypertension } \\
\text { With hypertension }\end{array}$ & $\begin{array}{l}30.29 \\
24.68\end{array}$ & $\begin{array}{l}13.93 \\
6.26\end{array}$ & $\begin{array}{l}12.03 \\
12.80\end{array}$ \\
\hline $\begin{array}{l}\text { Dietary Intake } \\
\text { Iron }\end{array}$ & & & \\
\hline $\begin{array}{l}\text { Inadequate } \\
\text { Adequate }\end{array}$ & $\begin{array}{c}7.96 \\
47.01\end{array}$ & $\begin{array}{c}1.51 \\
18.68\end{array}$ & $\begin{array}{c}4.22 \\
20.61\end{array}$ \\
\hline $\begin{array}{l}\text { Niacin } \\
\text { Inadequate } \\
\text { Adequate } \\
\text { More than adequate }\end{array}$ & $\begin{array}{c}30.07 \\
23.83 \\
1.07\end{array}$ & $\begin{array}{l}13.38 \\
6.56 \\
0.26\end{array}$ & $\begin{array}{l}10.19 \\
14.03 \\
0.61\end{array}$ \\
\hline $\begin{array}{l}\text { Thiamine } \\
\text { Inadequate } \\
\text { Adequate }\end{array}$ & $\begin{array}{c}4.48 \\
50.49\end{array}$ & $\begin{array}{c}1.17 \\
19.02\end{array}$ & $\begin{array}{c}2.72 \\
22.11\end{array}$ \\
\hline $\begin{array}{l}\text { Vitamin A } \\
\text { Inadequate } \\
\text { Adequate } \\
\text { More than adequate }\end{array}$ & $\begin{array}{c}0.96 \\
29.39 \\
24.62\end{array}$ & $\begin{array}{c}1.14 \\
12.91 \\
6.15\end{array}$ & $\begin{array}{c}0.20 \\
12.48 \\
12.15\end{array}$ \\
\hline
\end{tabular}


compared to the elderly belonging in the age group of 60-70 years old. With 95\% confidence, the true odds ratio for 71-80 years old and $>80$ years old adult lie in the range of 1.13-2.06, and 1.09-2.95, respectively. It can also be noted that an elderly was less likely to be underweight if he/she had hypertension. Particularly, the odds of an elderly being underweight was reduced by about $44 \%$ if he/she was hypertensive in comparison to one who had normal blood pressure. Similarly, it was 2.25 times more likely that an elderly was underweight if he/ she had inadequate vitamin A intake compared to one with enough intake of vitamin $\mathrm{A}$, with a $95 \%$ confidence limits of odds ratio between 1.14 and 4.42. Alternatively, it was less likely for an elderly to be underweight if he/she had an over-adequate intake of vitamin A compared to one with adequate intake,

Table 3. Estimated parameters of the logistic regression model for underweight among elderly in the Philippines

\begin{tabular}{|c|c|c|c|c|}
\hline Factor & Coefficient & Odds ratio & 95\% CI for odds ratio & $p$-value \\
\hline \multicolumn{5}{|l|}{ Underweight } \\
\hline Constant & -1.500 & & & 0.001 \\
\hline $\begin{array}{l}\text { Age group }{ }^{1} \\
71-80 \text { years } \\
>80 \text { years }\end{array}$ & $\begin{array}{l}0.422 \\
0.586\end{array}$ & $\begin{array}{l}1.52 \\
1.80\end{array}$ & $\begin{array}{l}{[1.13,2.06]} \\
{[1.09,2.95]}\end{array}$ & $\begin{array}{l}0.006 * * \\
0.021 *\end{array}$ \\
\hline $\begin{array}{l}\text { Hypertension }{ }^{2} \\
\text { Yes }\end{array}$ & -0.582 & 0.56 & {$[0.42,0.74]$} & $<0.001^{* * *}$ \\
\hline $\begin{array}{l}\text { Anaemia }^{3} \\
\text { Yes }\end{array}$ & 0.390 & 1.48 & {$[1.08,2.02]$} & $0.015 *$ \\
\hline $\begin{array}{l}\text { Adequacy of vitamin A ir } \\
\text { Inadequate } \\
\text { Over-adequate }\end{array}$ & $\begin{array}{c}0.810 \\
-0.375\end{array}$ & $\begin{array}{l}2.25 \\
0.69\end{array}$ & $\begin{array}{l}{[1.14,4.42]} \\
{[0.52,0.92]}\end{array}$ & $\begin{array}{l}0.019 * \\
0.011^{*}\end{array}$ \\
\hline \multicolumn{5}{|l|}{ Overweight } \\
\hline Constant & -1.559 & & & $<0.001$ \\
\hline $\begin{array}{l}\text { Highest educational atta } \\
\text { Elementary } \\
\text { High school } \\
\text { At least college level }\end{array}$ & $\begin{array}{l}0.472 \\
0.640 \\
1.039\end{array}$ & $\begin{array}{l}1.60 \\
1.90 \\
2.83\end{array}$ & $\begin{array}{l}{[1.14,2.26]} \\
{[1.26,2.86]} \\
{[1.72,4.65]}\end{array}$ & $\begin{array}{l}0.007^{* *} \\
0.002^{* *} \\
<0.001^{* * *}\end{array}$ \\
\hline $\begin{array}{l}\text { Anaemia }^{3} \\
\text { With anaemia }\end{array}$ & -0.578 & 0.56 & {$[0.38,0.83]$} & $0.004 * *$ \\
\hline $\begin{array}{l}\text { Hypertension }^{2} \\
\quad \text { With hypertension }\end{array}$ & 0.295 & 1.34 & {$[1.02,1.77]$} & $0.036 *$ \\
\hline $\begin{array}{l}\text { Diabetes }^{6} \\
\text { With diabetes }\end{array}$ & 0.639 & 1.89 & {$[1.33,2.69]$} & $<0.001 * * *$ \\
\hline $\begin{array}{l}\text { Dyslipidaemia } \\
\quad \text { With dyslipidaemia }\end{array}$ & 0.550 & 1.73 & {$[1.07,2.81]$} & $0.025 *$ \\
\hline
\end{tabular}

Base category: ${ }^{1} 60-70$ years; ${ }^{2}$ without anaemia; ${ }^{3}$ without hypertension; ${ }^{4}$ adequate;

${ }^{5}$ no grades completed; ${ }^{6}$ without diabetes; ${ }^{7}$ without dyslipidaemia

*significant at $p<0.05$

$* *$ significant at $p<0.01$

*** significant at $p<0.001$ 
with an odds ratio of 0.69 , wherein the true odds ratio is between 0.52 and 0.92 (Table 3).

When considering educational attainment, based on the fitted model, the likelihood of an elderly becoming overweight/obese was higher if he/ she reached elementary, high school, or at least college level and if one had hypertension, diabetes, and dyslipidaemia, holding other factors constant. Results of the modelling showed that, in particular, the odds for an elderly to be overweight/obese increased as educational attainment got higher, with the odds ratio of 1.60 , 1.90 , and 2.83 for those whose highest educational attainment were elementary, high school, and at least college level, respectively, relative to those recorded with no grades completed. The true odds ratio for elementary is within 1.14 to 2.26 , for high school: 1.262.86, and for at least college level: $1.72-4.65$, in relation to those with no grade completed at 0.95 level of confidence. It was estimated that elderly with hypertension, dyslipidaemia, and diabetes mellitus were $1.34,1.73$, and 1.89 times more likely to be overweight/ obese, respectively in comparison with elderly individuals who were not suffering from these said diseases. Moreover, a 95\% confidence limits showed that true odds ratio for hypertension, diabetes, and dyslipidaemia are within $[1.02,1.77],[1.33,2.69]$, and [1.07, $2.81]$, respectively, over without these diseases. Meanwhile, the estimated model revealed that the odds of an elderly being overweight was reduced by about $44 \%$ if he/she had anaemia, with a true odds ratio lies between 0.38 and 0.83 . This was consistent with the result of the fitted model for those underweight in which the likelihood of the latter was higher in the presence of anaemia (Table 3).

We noted that both the fitted models were significant ( $p$-value of $<0.0001$ ); hence, the overall model fitted the data for both underweight and overweight. Likewise, the Receiver Operating Characteristic (ROC) revealed 65.6\% area under the curve for underweight. Since it covered more than $50 \%$ of the

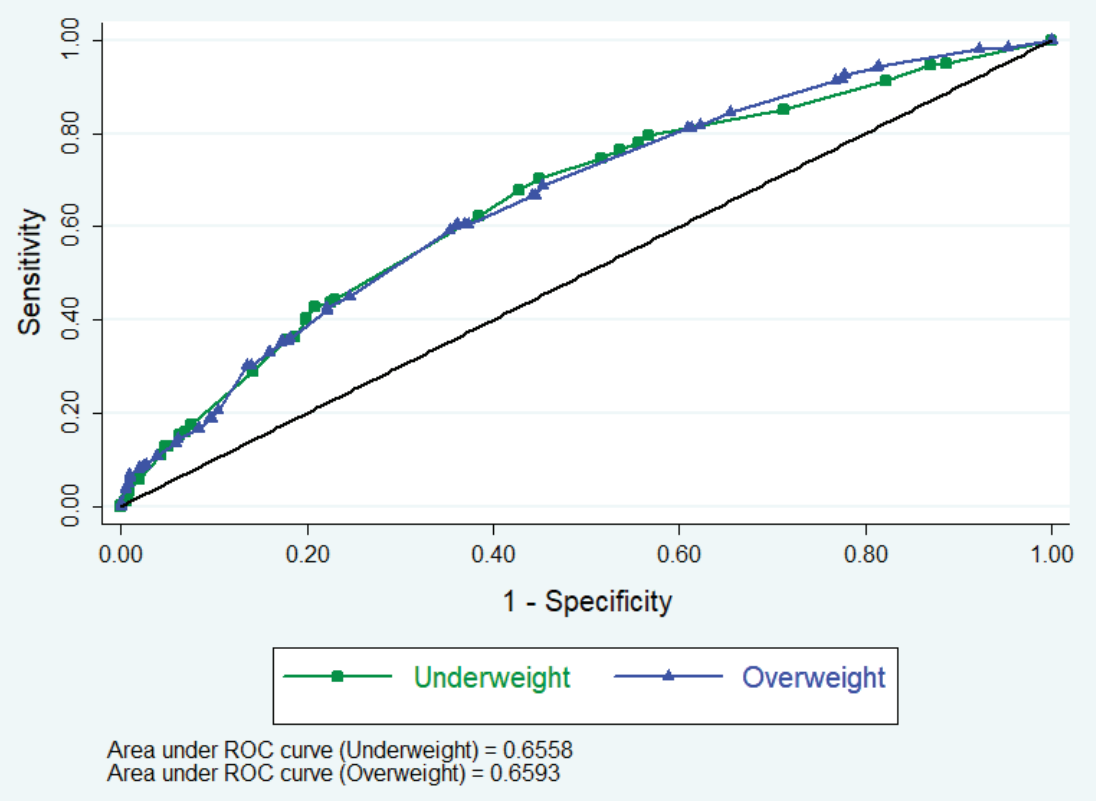

Figure 2. ROC curve of the fitted model for overweight and underweight Filipino elderly 
reference line, the model is said to have a fair predicting power. Similarly, the fitted model for the likelihood of overweight gave a fair predicting power, with an area under the ROC curve of 66\% (Figure 2).

\section{DISCUSSION}

Nutritional status across some factors Although the majority of the Filipino elderly were assessed to have a normal nutritional status, considerably high portions of them were either underweight or overweight. Results showed alarming values, which may imply that the elderly population are exposed to malnutrition. More females than males were found experiencing malnutrition. Similar results were found by Rawal et al. (2016) in their study about the prevalences of underweight, overweight, and obesity, and their associated risk factors among Nepalese adults where the proportions of underweight and overweight were high among female adults compared to male adults. In their studies, Boulos et al. (2013) and Saeidlou et al. (2011) also found a significant positive association between being a female and nutritional status. Also, the proportion of underweight and overweight/ obesity decreased as age of the elderly increased. In the study of Coqueiro et al. (2010), the prevalence of underweight was higher in older age groups, while the prevalence of overweight was higher in younger age groups. However, other existing literature showed that older age groups have poorer nutritional status compared with younger age groups (Kyle et al., 2002; Forster \& Gariballa, 2005; Agarwalla et al., 2015).

Among the underweight elderly, many of them had no formal education, while many of the overweight/obese attained elementary education. In the study of Rawal et al. (2018), the elderly who had no education were more likely to be underweight and less likely to be overweight or obese compared to those who were at least college graduates. Moreover, Poda et al. (2019) found that no formal education was positively associated with undernutrition in older adults. Similar to the other studies' results (Poda et al., 2019; Rawal et al., 2018; Pradeepa et al., 2015; Katulanda et al., 2010), this study found that the prevalence of overweight/obesity was higher among the elderly who were actively working compared to those with no occupation or low earners. However, other research showed otherwise; those with no or lower income were more likely to be underweight than overweight/ obese (Ferdous et al., 2009; Han, Li \& Zheng, 2009; Saikia \& Mahanta, 2013).

This study also showed that most elderly who did not smoke and were nonalcoholic fell under the normal nutritional status classification. Nonetheless, a greater portion of malnourished elderly who smoked (former smoker and current smoker) were assessed as underweight. In contrast, more elderly Filipinos with malnutrition and consumed alcohol (alcoholic and drinks alcohol occasionally) were overweight/ obese. Research has shown that nicotine in cigarettes increases metabolic rate (WHO, 1995) and reduces appetite (Chiolero et al., 2008), which results in lower weight (Fares et al., 2012). On the other hand, alcohol can stimulate food intake (Yeomans, 2010), which further results in weight gain.

It can also be observed that more elderly Filipinos with normal nutritional status had adequate intakes of iron, thiamine, and vitamin A. Looking at those with malnutrition, there were more overweight/obese than underweight elderly who had an adequate intake of iron, niacin, thiamine, and vitamin A. A greater portion of the underweight population was observed to lack an adequate niacin intake. In the study of Baugreet et al. (2017), inadequate macroand micronutrient intakes, which is a result of low food intake in older adults 
(Hickson, 2006), contributed to weight loss and malnutrition. However, Leslie \& Hankey (2015) reported that shortage in micronutrient intakes was accompanied by a high incidence of overweight and obesity, which according to Astrup \& Bugel (2019), is possibly a result of poor diet quality (i.e. overconsumption of high-calorie, low-nutrient processed foods).

According to existing studies (Chavarro-Carvajal et al.; 2015, Peng et al., 2015; Poda et al., 2019), health conditions and comorbidities contribute to malnutrition in older adults, such as diabetic elderly patients having a higher risk of suboptimal nutrition (Sanz-Paris \& Lardies-Sanchez, 2019). In terms of the elderly's health conditions, a greater portion of those who were overweight/ obese had diabetes, dyslipidaemia, and hypertension compared to those who were underweight. This is similar with the findings of Lu et al. (2018) where elderly patients who were hypertensive, insulin resistant, and had lower highdensity lipoprotein cholesterol levels had higher BMI. Specifically, obesity is closely associated with systematic hypertension, glucose intolerance, diabetes mellitus, and dyslipidaemia (Ho et al., 2001; Jonsson et al., 2002; Dalton et al., 2003). Both systolic and diastolic blood pressure values are linearly correlated with BMI (Mungreiphy, Kapoor \& Sinha, 2011; Landi et al., 2018). Irregularities in lipid metabolism are also very common in obese individuals (Feingold \& Grunfeld, 2000).

Meanwhile, more underweight elderly Filipinos were anaemic compared to those who were overweight/obese. Gupta et al. (2011) and Ramachandra \& Kasthuri (2008) reported that underweight elderly had a higher prevalence of anaemia. Anaemic elderly individuals have low dietary, energy, and protein intakes, resulting in lower quantity of food consumption (Gupta et al., 2020). Furthermore, anaemia among the elderly has been shown to play a role in the development of frailty, a condition characterised by weight loss, weakness, impaired mobility, and poor balance (Kikuchi, Inagaki \& Shinagawa, 2001; Woodman, Ferrucci \& Guralnik, 2005).

\section{Influencing factors}

The fitted model indicated that the likelihood of an elderly to become underweight was higher if he/she was $\geq$ 70 years old. As one ages, there will be more hormones that decrease appetite and fewer neurotransmitters to excite the appetite, which cause the elderly to eat less. Consequently, because of inadequate intake, undernutrition among the elderly is often part of the general decline (Zagaria, 2010). Also, ageing in humans is accompanied by changes (Forster \& Gariballa, 2005), such as reduced sense of smell and taste, oral cavity problems, and declined cognitive and functional capacities (Population Reference Bureau, 2007), which may further result to being underweight (Fares et al., 2012).

Meanwhile, an elderly individual was more likely to be underweight if he/she had anaemia. This result is consistent with the study of Imai et al. (2016) where they found that anaemic subjects tended to have lower BMI. This may be due to nutrient deficiency such as haemoglobin and iron count. These observations are similar with previous studies, specifically in the study of Poda et al. (2019) wherein characteristics such as age $>70$ years, gender, uneducated level, low income, and having anaemia were positively associated with undernutrition among older adults.

Regarding nutrient intake, it was more likely that an elderly will be underweight if one has inadequate intake of vitamin A. Some of the common reasons cited for inadequate nutrient intake were problems in chewing and swallowing, digesting, and absorbing nutrients (Chernoff, 2005). Other reasons could be the incapacity of the elderly to make decisions about food intake and the lack 
of financial support (Agarwalla et al., 2015).

Furthermore, this study found that an elderly with hypertension was less likely to be underweight. A similar finding was reported in the studies of Assumpcão et al. (2018) and Francisco et al. (2019) where being underweight was less prevalent among hypertensive older adults.

In the case of being overweight/ obese, having attained elementary, high school, or at least college education level, and having hypertension, diabetes, and dyslipidaemia were found as significant determinants. Education may be connected to the wealth of an individual. Normally, the higher the educational attainment, the higher the income; therefore, they are able to meet and even exceed the recommended food intake (Ahmed \& Haboubi, 2010). The same result was revealed by the studies of Barreto, Passos \& Lima-Costa (2003), Bovet et al. (2008), and Wang et al. (2009) wherein they observed that education played a role in the nutritional status of the elderly. The higher the educational attainment, the higher the income, and more knowledgeable individuals were about nutritional needs; thus, they were able to consume, meet, and even exceed the recommended food intake.

Likewise, results also showed that it was more likely for an elderly to be overweight if he/she had dyslipidaemia, since this said disease is about an abnormal amount of lipids like triglycerides and cholesterol (bad and good) in the body which affects nutritional status. Similar to reports from previous literature, if an elderly has hypertension, their BMI is expected to be higher. Obesity is associated with hypertension since body fats affect systolic and diastolic blood pressure, and hypertension is associated with numerous other diseases that can affect overall health and life expectancy (Delaney, 2009). This is also supported by the studies of Cameron et al. (2008),
Srinivasan et al. (2009), and Hsieh \& Muto (2006) whose results showed that being overweight and being obese are accompanied by cardiovascular disease risk, such as hypertension, dyslipidaemia, diabetes mellitus, and insulin resistance.

In contrast, having anaemia reduced the likelihood of an elderly becoming overweight/obese. This is consistent with the result of the fitted model for underweight, in which the likelihood of the latter was higher in the presence of anaemia.

The strong point of this study was that the model constructed was based on the nationwide data obtained from the $8^{\text {th }}$ NNS conducted by FNRI, representing the elderly in the Philippines. The limitation of the study was that the dependent variable considered was the nutritional status of elderly, based on BMI, to address the primary objective of the study. Conclusions made from the study reflect only nutritional status as a response characteristic, while clinical and health, dietary, and socioeconomic characteristics of the elderly were explanatory variables. Any possible comorbidities between the dependent and the considered explanatory variables were not considered in the study.

\section{CONCLUSION AND RECOMMENDATION}

This study determined the nutritional status of the elderly based on their BMI across some considered factors and identified possible influencing factors based on socioeconomic, clinical and health conditions, and nutrient intakes using the 2013 NNS data. It is important to note that all of the health conditions included in this study influenced the nutritional status of the elderly. The odds of becoming overweight increased if the elderly had diabetes, dyslipidaemia, and hypertension. While the odds of being underweight was higher if an elderly had anaemia. Although anaemia, diabetes 
and dyslipidaemia are not as prevalent as hypertension, necessary actions must be implemented to assess these risk factors as these affect the nutritional status of Filipino elderly in a negative manner. Despite the high percentage of elderly with adequate nutrient intake, it is also important to note that nutrient intake was a determinant of nutritional status among the elderly population, especially vitamin A intake. Thus, elders should consume foods that are rich with such nutrient.

This study will be helpful in addressing the issue on malnutrition by finding the factors that influence nutritional status of the elderly. Knowing the factors will help the elderly become more aware and conscious of their health and nutrient intakes to prevent malnutrition that can worsen their health conditions. Also, the concerned institutions would be able to strengthen their approach and implementation or even provide relevant and timely policies and programmes using the factors that were found to be significantly associated with the nutritional status among Filipino elderly. Particularly, strategies on how to improve the health conditions and dietary intake of Filipino elderly must be implemented to improve their nutritional status. This study could also be used as the basis for future studies as malnutrition in the elderly is not popular in the Philippines.

Nutritional status of the elderly could be examined comprehensively based on one's anthropometric measurement, medical history, and nutritional history such as appetite, change in food intake, and weight change (JASPEN, 2013). This study was carried out to characterise the malnourished elderly based only on anthropometric measurement, which was BMI, using the 2013 NNS data, with the cutoff values recommended by WHO. The accuracy of BMI depended on the measurement that was done by the institute who conducted the survey. Also, to identify determinants of malnutrition among Filipino elderly, only socioeconomic, health and clinical, and dietary data available in the 2013 NNS were considered. Therefore, it is recommended to use more recent data as there may be variations in the determinants of nutritional status of Filipino elderly. Besides that, it is also recommended to include other components from the survey that may have a relationship with the nutritional status of elderly. Future studies can consider factors such as housing characteristics and living arrangements for these may contribute to the nutritional status of elderly. Psychological factors that are very prevalent among the elderly and are affecting their eating habits, as well as eating disorders, may also be considered for a more comprehensive perspective to adequately assess and interpret the nutritional status of elderly people. Similarly, psychological factors, such as depression and loneliness that affect the nutritional status of elderly can also be studied. Future studies can also take into account other medical factors such as mouth pain, chewing and swallowing disorders and visual or hearing impairments. Finally, residential status (urban or rural) can also be considered as one of the explanatory variables in future related studies, with the consideration of lifestyle differences of people residing in the urban and rural areas, and in the healthcare systems present in their areas.

\section{Acknowledgement}

The authors are grateful to the Food and Nutrition Research Institute - Department of Science and Technology, Philippines for the 2013 National Nutrition Survey data.

\section{Authors' contributions}

NAT, conceptualised, designed and prepared the manuscript; RLCA, conducted data analysis and reviewed related articles; GCN, conducted review of related literatures. All authors interpreted the results of analysis, read and approved the manuscript. 


\section{Conflict of interest}

The authors declared no conflict of interest.

\section{References}

Agarwalla R, Saikia AM \& Baruah R (2015). Assessment of the nutritional status of the elderly and its correlates. J Fam Community Med 22(1):39-43.

Ahmed T \& Haboubi N (2010). Assessment and management of nutrition in older people and its importance to health. Clin Interv Aging 5:207-216

Assumpção D, Borim FSA, Francisco PMSB \& Neri AL (2018). Fatores associados ao baixo peso em idosos comunitários de sete cidades brasileiras: Estudo FIBRA. Cien Saude Colet 23(4):1143-1150.

Astrup A \& Bugel S (2019). Overfed but undernourished: recognizing nutritional inadequacies/deficiencies in patients with overweight or obesity. Int J Obes 43:219-232.

Barcenas ML (2004). The Development of the 2003 Master Sample (MS) for Philippine Household Surveys. 9th National Convention on Statistics, Philippines.

Barreto SM, Passos VM \& Lima-Costa MF (2003). Obesity and underweight among Brazilian elderly: the Bambui Health and Aging Study. Cad Saude Publica 19(2):605-612.

Baugreet S, Hamill RM, Kerry JP \& McCarthy SN (2017). Mitigating nutrition and health deficiencies in older adults: a role for food innovation? J Food Sci 82(4):848-855.

Boscatto EC, Duarte MD, Coqueiro RD \& Barbosa AR (2013). Nutritional status in the oldest elderly and associated factors. Associação Médica Brasileira 59(1):40-47.

Boulos C, Salameh P \& Barberger-Gateau P (2013). The AMEL study, a cross sectional populationbased survey on aging and malnutrition in 1200 elderly Lebanese living in rural settings: Protocol and sample characteristics. BMC Public Health 12(13):573.

Bovet P, Chiolero A, Shamlaye C \& Paccaud F (2008). Prevalence of overweight in the Seychelles: 15 year trends and association with socio-economic status. Obes Rev 9(6):511-517.

Cameron AJ, Boyko EJ, Sicree RA, Zimmet PZ, Söderberg S, Alberti KGMM, Tuomilehto J, Chitson P \& Shaw JE (2008). Central obesity as a precursor to the metabolic syndrome in the AusDiab study and Mauritius. Obesity (Silver Spring) 16:2707-2716.
Chavarro-Carvajal D, Reyes-Ortiz C, SamperTernent R, Arciniegas AJ \& Gutierrez CC (2015). Nutritional assessment and factors associated to malnutrition in older adults: a cross-sectional study in Bogotá, Colombia. $J$ Aging Health 27:304-319.

Chernoff $\mathrm{R}$ (2005). Micronutrient requirements in olderwomen. AmJClin Nutr81(5):1240S-1245S.

Chiolero A, Faeh D, Paccaud F \& Cornuz J (2008). Consequences of smoking for body weight, body fat distribution, and insulin resistance. Am J Clin Nutr 87:801-809.

Coqueiro RDS, Barbosa AR \& Borgatto AF (2010). Nutritional status, health conditions and sociodemographic factors in the elderly of Havana, Cuba: Data from Sabe Survey. J Nutr Health Aging 14:803-808.

Dalton M, Cameron AJ, Zimmet PZ, Shaw JE, Jolley D, Dunstan DW, Welborn TA \& AusDiab Steering Committee (2003). Waist circumference, waist-hip ratio and body mass index and their correlation with cardiovascular disease risk factors in Australian adults. $J$ Intern Med 254(6):555-563.

Delaney J (2009). In: Hypertension and Obesity: How Weight-loss Affects Hypertension. From https://www.obesityaction.org/community/ article-library/hypertension-and-obesity-howweight-loss-affects-hypertension/ [Retrieved December 1, 2019].

Fares D, Barbosa AR, Borgatto AF, Coqueiro RS \& Fernadez MH (2012). Factors associated with the nutritional status of the elderly in two regions of Brazil. Rev Assoc Med Bras 58(4):434-441.

FNRI-DOST (2013). Philippine Nutrition Facts and Figures 2013. From http://enutrition.fnri. dost.gov.ph/assets / uploads / publications / Overview_8thNNS_050416.pdf [Retrieved November 16, 2019].

Feingold KR \& Grunfeld C (2000). Obesity and Dyslipidemia. In KR Feingold, B Anawalt, A Boyce et al. (eds.). Endotext. MDText.com, Inc. South Dartmouth.

Ferdous T, Kabir ZN, Wahlin A, Streatfield K \& Cederholm T (2009). The multidimensional background of malnutrition among rural older individuals in Bangladesh - A challenge for the Millennium Development Goal. Public Health Nutr 12:2270-2278.

Forster S \& Gariballa S (2005). Age as a determinant of nutritional status: A cross sectional study. Nutr J 4:28. 
Francisco P, Assumpcão D, Borim F \& Malta D (2019). Prevalence and factors associated with underweight among Brazilian older adults. Ciência \& Saúde Coletiva 24(7):2443-2452.

Gupta VK, Maria AK, Kumar R, Bahia JS, Arora S, Singh R, Shelza \& Gupta V (2011). To study the prevalence of anaemia in young males and females with respect to the age, body mass index (BMI), activity profile and the socioeconomic status in rural Punjab. $J$ Clin Diagn Res 5(5):1020-1026.

Gupta A, Ramakrishnan L, Pandey RM, Sati HC, Khandelwal R, Khenduja P \& Kapil U (2020). Risk factors of anemia amongst elderly population living at high-altitude region of India. J Family Med Prim Care 9(2):673-682.

Han Y, Li S \& Zheng Y (2009). Predictors of nutritional status among community-dwelling older adults in Wuhan, China. Public Health Nutr 12:1189-1196.

HelpAge International (2012). In: Ageing population in the Philippines. From https://ageingasia. org/ageing-population-philippines/ [Retrieved December 1, 2019].

Hsieh SD \& Muto T (2006). Metabolic syndrome in Japanese men and women with special reference to the anthropometric criteria for the assessment of obesity: Proposal to use the waist-to-height ratio. Prev Med 42:135-139.

Hickson M (2006). Malnutrition and ageing. Posgrad Med $J$ 82:2-8.

Ho SC, Chen YM, Woo JL, Leung SS, Lam TH \& Janus ED (2001). Association between simple anthropometric indices and cardiovascular risk factors. Int $J$ Obes Relat Metab Disord 25(11):1689-1697.

Imai $\mathrm{E}$, Nakade $\mathrm{M}$, Tsuboyama $\mathrm{K}$ \& Takimoto $\mathrm{H}$ (2016). Improved Prevalence of anemia and nutritional status among Japanese elderly participants in the National Health and Nutritional Survey Japan, 2003-2009. Journal of Nutrition \& Food Sciences 50-62.

JASPEN (2013). JASPEN guidelines on parenteral and enteral nutrition. 3rd ed. Japanese Society for Parenteral and Enteral Nutrition. Shorinsha Inc., Tokyo.

Jonsson S, Hedblad B, Engstrom G, Nilsson P, Berglund G \& Janzon L (2002). Influence of obesity on cardiovascular risk. Twenty-threeyear follow-up of 22,025 men from an urban Swedish population. Int $J$ Obes Relat Metab Disord 26(8):1046-5103.

Katulanda P, Jayawardena M, Sheriff M, Constantine G \& Matthews D (2010). Prevalence of overweight and obesity in Sri Lankan adults. Obes Rev 11(11):751-756.
Kyle UG, Unger P, Mensi N, Genton L \& Pichard C (2002). Nutrition status in patients younger and older than $60 \mathrm{y}$ at hospital admission: A con- trolled population study in 995 subjects. Nutrition 18:463-469.

Kikuchi M, Inagaki T \& Shinagawa N (2001). Fiveyear survival of older people with anemia: variation with hemoglobin concentration. $\mathrm{J} \mathrm{Am}$ Geriatr Soc 49(9):1226-8.

Landi F, Calvani R, Picca A, Tosato M, Martone AM, Ortolani E, Sisto A, D'Angelo E, Serafini E, Desideri G, Fuga MT \& Marzetti E (2018). Body mass index is strongly associated with hypertension: Results from the Longevity Check-Up 7+ Study. Nutrients 10(12):1976.

Leslie W \& Hankey C (2015). Aging, nutritional status and health. Healthcare (Basel) 3(3):648658.

Lu C, Li X, Ming-Ya W \& Yu-Guang H (2018). Obesity paradox among elderly patients with coronary artery disease undergoing noncardiac surgery. J Geriatr Cardiol 15:598-604.

Ly KA, Ton TGN, Ngo QV \& Fitzpatrick AL (2013). Double burden: a cross-sectional survey assessing factors associated with underweight and overweight status in Danang, Vietnam. BMC Public Health 13: 35.

Marengoni A, Winblad B, Karp A \& Fratiglioni L (2008). Prevalence of chronic diseases and multimorbidity among the elderly population in Sweden. Am J Public Health 98(7):1198-2000.

Mungreiphy NK, Kapoor S \& Sinha R (2011). Association between BMI, blood pressure, and age: Study among Tangkhul Naga Tribal males of Northeast India. J Anthropol 2011:1-6.

Panigrahi AK (2009). Determinants of Living Arrangements of Elderly in Orissa. The Institute for Social and Economic Change 2009, Bangalore. From http://www.isec.ac.in/ WP\%20228\%20-\%20Akshaya\%20Kumar\%20 Panigrahi.pdf [Retrieved December 01, 2019].

Peng LN, Cheng Y, Chen LK, Tung $\mathrm{HH}$, Chu KH $\&$ Liang SY (2015) Cognition and socialphysiological factors associated with malnutrition in hospitalized older adults in Taiwan. J Nurs Res 23:1-5.

Poda GG, Hsu CY, Rau HH \& Chao JCJ (2019). Impact of socio-demographic factors, lifestyle and health status on nutritional status among the elderly in Taiwan. Nutr Res Pract 13(3):222229.

Population Reference Bureau (2007) Underweight, undernutrition, and the aging. Today's Res Aging. From http://www.prb.org/pdf07/ TodaysResearchAging8.pdf [Retrieved May 15, 2020]. 
Pradeepa R, Anjana RM, Joshi SR, Bhansali A, Deepa M, Joshi PP, Dhandania VK, Madhu SV, Rao PV, Geetha L, Subashini R, Unnikrishnan R, Shukla DK, Kaur T, Mohan V, Das AK \& the ICMR-INDIAB Collaborative Study Group (2015). Prevalence of generalized \& abdominal obesity in urban \& rural India- the ICMRINDIAB Study (Phase-I) [ICMR-INDIAB-3]. Indian J Med Res 142(2):139-50.

Ramachandra SS \& Kasthuri A (2008). Anaemia in the elderly who resided in a south Indian rural community. Indian Journal for the Practicing Doctor 5(4):2-7.

Rawal LB, Kanda K, Mahumud RA, Joshi D, Mehata S, Shrestha N, Poudel P, Karki S \& Renzaho A (2016). Prevalence of underweight, overweight and obesity and their associated risk factors in Nepalese adults: data from a Nationwide Sruvey. PLos One 13(11): e0205912. doi: 10.1371/journal.pone.0205912. eCollection 2018.

Saeidlou SN, Merdol TK, Mikaili P \& Bektas Y (2011). Assessment of the nutritional status and affecting factors of elderly people living at six nursing home in Urmia, Iran. Part I. Int $J$ Acad Res 3(1):173-181.

Saikia A \& Mahanta N (2013). A study on nutritional status of elderly in terms of body mass index in Urban Slums of Guwahati City. $J$ Indian Acad Geriatr 9:11-14.

Sanz-París A \& Lardiés-Sánchez B (2019). Nutritional Status in Malnourished Older Diabetics. In Preedy $\mathrm{V} \&$ Patel V (eds). Handbook of Famine, Starvation, and Nutrient Deprivation. Springer, Cham.

Selvamani Y \& Singh P (2018). Socioeconomic patterns of underweight and its association with self-rated health, cognition and quality of life among older adults in India. PLos One 13(3):e0193979. doi: 10.1371/journal. pone.0193979. eCollection 2018.

Shibata Yosuke, Toshiyuki Ojima, Mieko Nakamura, Kazuyo Kuwabara, Naoko Miyagawa, Yoshino Saito, Yasuyuki Nakamura, Yutaka Kiyohara, Hideaki Nakagawa, Akira Fujiyoshi, Aya Kadota, Takayoshi Ohkubo, Tomonori Okamura, Hirotsugu Ueshima, Akira Okayama, Katsuyuki Miura (2019). Associations of Overweight, Obesity, and Underweight With High Serum Total Cholesterol Level Over 30 Years Among the Japanese Elderly: NIPPON DATA 80, 90, and 2010. Journal of Epidemiology Volume 29 Issue 4 Pages 133-138. do: https://doi. org/10.2188/jea.JE20170229
Srinivasan SR, Wang R, Chen W, Wei CY, Xu J \& Berenson GS (2009). Utility of waist-toheight ratio in detecting central obesity and related adverse cardiovascular risk profile among normal weight younger adults (from the Bogalusa Heart Study). Am J Cardiol. 104:721724.

Wang Y, Chen HJ, Shaikh S \& Mathur P (2009). Is obesity becoming a public health problem in India? Examine the shift from under- to overnutrition problems over time. Obes Rev 10(4):456-474.

WHO/NCHS (1978). 1978 WHO/NCHS Growth References. WHO, Geneva.

WHO (1995). Physical status: the use and interpretation of anthropometry. Report of a WHO Expert Committee. Technical Report Series $N^{\circ}$ 854. World Health Organization, Geneva.

WHO (2018). In: Ageing and health. World Health Organization. From https://www.who.int/ news-room/fact-sheets / detail/ageing-andhealth [Retrieved December 01, 2019].

Woodman R, Ferrucci L \& Guralnik J (2005). Anemia in older adults. Curr Opin Hematol 12(2):123-8.

Yeomans MR (2010). Alcohol, appetite and energy balance: is alcohol intake a risk factor for obesity? Physiol Behav 100:82-89.

Zagaria MAE (2010). In: Vitamin deficiencies in seniors. US Pharmacist. From https:// www.uspharmacist.com/article/vitamindeficiencies-in-seniors [Retrieved November 10, 2019]. 